\title{
The Effect of Pregnant Mare Serum Gonadotrophin (PMSG) and GnRH Injection on Weaning to Oestrus Interval and Litter Size of Artificially Inseminated Sows
}

\author{
K.K. Sarath ${ }^{*}$, Anil Pushpakumara ${ }^{1}$ and Basil Alexander ${ }^{1}$ \\ Department of Animal Production and Health \\ Welisara, Sri Lanka
}

\begin{abstract}
This experiment was carried out to investigate the effect of exogenous pregnant mare serum gonadotrophin (PMSG) and gonadotrophin-releasing hormone $(G n R H)$ on weaned sows bred by artificial insemination. Chilled semen at 24 hours after the onset of standing heat was used for the experiment. In the treatment group (experiment 1), sows $(n=32)$ were injected with 500 IU of PMSG at weaning and $50 \mu g$ of GnRH injection was given at the time of insemination. As the control, sows $(n=33)$ were inseminated without giving any hormones. Weaning to estrus interval, conception rate and litter size were recorded. Results were analyzed using the Minitab Statistical Software version 14, 2010. The means were compared using the Student's t-test. Results revealed that in group 1, the PMSG treated sows had significantly $(p<0.05)$ lower mean interval from weaning to estrus compared to that of the control group $(4.7 \pm 0.51$ and $20.15 \pm 0.81$ respectively). The mean litter size of PMSG-treated Durock sows was significantly lower compared to that of the control group $(4.3 \pm 4.3$ and $8.7 \pm 0.9)$, while the conception rate in the treated group was significantly higher $(76.6 \%$; $<<0.05)$ compared to that of the control group $(39.3 \%)$.
\end{abstract}

Keywords: Gonadotrophin, oestrus interval, litter size, sows

\section{INTRODUCTION}

As production demand increases sows are expected to produce more offspring during their lifespan. To achieve this goal sows must be attained puberty at earlier age, bred and become pregnant first time of mating, farrowing larger litter, wean large number of healthy piglets and return to estrus in a shorter period of time after weaning. It is very difficult to achieve this goal only by management practice. Therefore, it is important to investigate the ways to improve the reproductive efficiency in sows. It is well known that manipulation of the estrous cycle using exogenous reproductive hormones plays a key role in pig breeding. Exogenous hormones can be used to influence puberty in gilts, estrus synchronization of sows and to minimize the interval between weaning and estrus (Zak et al., 2007).

Many studies have been carried out to investigate how oestrous cycle of the sow can be manipulated to get maximum production. It has been demonstrated that ovarian activity in

\footnotetext{
Faculty of Veterinary Medicine and Animal Science, University of Peradeniya, Sri Lanka

Corresponding author: kahandakanaththage@yahoo.co.in
} 
the lactating sow can be induced by reducing the frequency of suckling stimuli of piglets (Burger 1952; Smith 1961; Crighton 1970). When sows were injected with 1000 to $2000 \mathrm{IU}$ (Coles and Hughes, 1946) of Pregnant Mare Serum Gonadotrophin (PMSG) after 40 days of farrowing, 86-96\% sows had shown estrus signs (Heitman and Cole 1956; Coles and Hughes 1946). In another study, when PMSG was injected on day 20 of post partum only $20 \%$ (Cole and Hughes, 1946) of the sows showed oestrous signs. Kuo et al. (1976) showed that when PMSG treatment was followed by hCG, $85 \%$ of sows exhibited estrus.

Artificial Insemination has been introduced recently to breed sows in few veterinary ranges in Western Province of Sri Lanka. Natural mating/service has been the main breeding tool practiced by all pig farmers across the island to breed their sows. As a result reproductive hormones had limited application in swine reproduction and dearth of information on use of hormones in swine farms. Therefore the present study was carried out to investigate the effect of PMSG on weaning to oestrus interval and litter size of artificially bred sows in Katana Veterinary Range.

\section{MATERIALS AND METHODS}

\section{Selection of sows}

This study was conducted from July 2009 to October 2010 in medium scale swine farms in the Katana Veterinary range. All the selected farms managed their sows intensively and keep accurate records on reproductive performance of their stock. Sows in a farm were allocated randomly to both groups and total of 11 farms used for this experiment.

\section{Objectives and experiment design}

The objectives of this experiment were to evaluate the effects of PMSG administered on day of weaning and to investigate the weaning to oestrous interval and the litter size in artificially bred sows. Two groups of sows served as treatment and control groups.

Treatment group: Thirty two $(\mathrm{n}=32)$ sows between parities 1-3 were randomly selected for this group. Durock $(\mathrm{n}=11)$, Land Race $(\mathrm{n}=9)$ and Large White $(\mathrm{n}=12)$ breeds of sows were included for the experiment. Sows were fed with commercial sow feed after farrrowing. Sows were weaned eight weeks after the farrowing and injected with 500 IU of PMSG (Veyx-Pharma GmbH, Germany) intramuscularly on the same day.

Following PMSG injection sows were observed few days for signs of estrus and back pressure test was applied to detect the standing heat. AI was performed 24 hours after the standing heat as described below. Immediately following AI, sows were injected with $50 \mu \mathrm{g}$ of Gonadotrophin Releasing Hormone (GnRH agonist -Gonadorelin, Depherelin, VeyxPharma, GmbH, Germany) intramuscularly. GnRH dose were decided according to the manufacturers guide line.

Control group: Thirty three sows $(\mathrm{n}=33)$ as described in treatment group were randomly selected for this group. Same breeds and sows from $1^{\text {st }}$ to $3^{\text {rd }}$ parity as in treatment group were included in the control group. After farrowing, these sows were also fed with same commercial sow feed. Sows were weaned eight weeks after the farrowing and no hormonal treatment was given to sows in this group. Sows were observed for estrus (natural) signs as 
in treatment group. Standing heat was detected by back pressure test and AI was performed 24 hours after the standing heat as described below.

A sow card was used to record the data and included history of the farm management, previous and present wean to estrus interval, litter size at furrowing and after 30 days after furrowing, breeds of sows, parity, breeding history, date of AI.

\section{Artificial insemination procedure}

Artificial insemination was done using chilled semen which was prepared in the Kotadeniyawa swine breeding unit. Semen was diluted extender was prepared dissolving following ingredient in one liter of distilled water.

Glucose -40.69 gr.

Tri-Nadium citrate-6gr

EDTA-1.25gr

$\mathrm{NaHCO} 3-1.25 \mathrm{gr}$

$\mathrm{KCl}-0.75 \mathrm{gr}$ and Neomycine $-1 \mathrm{gr}$

Sow was properly restrained and vulva was cleaned using a paper towel. The tip of the AI catheter was lubricated using semen extender before insemination. Catheter was inserted into the vulva and solely guided it into the cervix while rotating counter- clockwise until it became engaged with cervix. Once the catheter was engaged in the cervix, semen filled plastic container was fixed to the catheter and gently pressed the container to release semen slowly into the uterus. Immediately following semen deposition, the catheter was removed by rotating clock wise gently. After insemination, all equipment were cleaned and packed properly. Date of AI, sow number, boar number, and parity of the sow and history of the sow were recorded in the card. Farmer was advised to observe inseminated sows 21 days for next heat. If the animals were not returned to heat, they were looked after until furrowing. Litter size at furrowing and litter size after one month were recorded.

\section{Statistical analysis}

The recorded data was analyzed using Minitab Statistical Software (Version 14, 2010) package. The Means were compared between treatment and control groups using Student's $t$-test. The significant level was calculated as $\mathrm{P}<0.05$ level.

\section{RESULTS}

Following PMSG injection $93.7 \%$ (30/32) of the sows showed estrous signs and positive for the back pressure test. The mean weaning to estrus interval of treatment group was $4.7 \pm 0.51$ days (Mean \pm SEM) with a range of 2 to 15 days (Table 1, Fig. 1). The mean weaning to estrus interval in the control group was $20.15 \pm 0.81$ days with a range of 8 to 30 days. All the sows in the control group returned to estrus during this period. The mean weaning to estrus interval in treatment group was significantly lower $(p<0.05)$ than that of the control group (Fig 1). 
Table 1. The mean weaning to estrus interval (Mean \pm SEM) and pregnancy rates in treated and control sows.

\begin{tabular}{lcccc}
\hline Treatment group & $\begin{array}{c}\text { No. of sows } \\
\text { showed estrus }\end{array}$ & $\begin{array}{c}\text { Mean weaning } \\
\text { to estrus } \\
\text { interval (days) }\end{array}$ & $\begin{array}{c}\text { No.of sows } \\
\text { conceived }\end{array}$ & $\begin{array}{c}\text { Pregnancy } \\
\text { rate \% }\end{array}$ \\
\hline $\begin{array}{l}\text { PMSG-Group 1 } \\
(\mathrm{n}=32)\end{array}$ & 30 & $4.7 \pm 0.5^{\mathrm{a}}$ & 23 & $76.6^{\mathrm{a}}$ \\
$\begin{array}{l}\text { Control-Group 2 } \\
(\mathrm{n}=33)\end{array}$ & 33 & $20.15 \pm 0.81^{\mathrm{b}}$ & 13 & $39.3^{\mathrm{b}}$ \\
\hline
\end{tabular}

(Superscripts $\boldsymbol{a}$ and $\boldsymbol{b}$ are significantly different $(P<0.05)$ between groups).

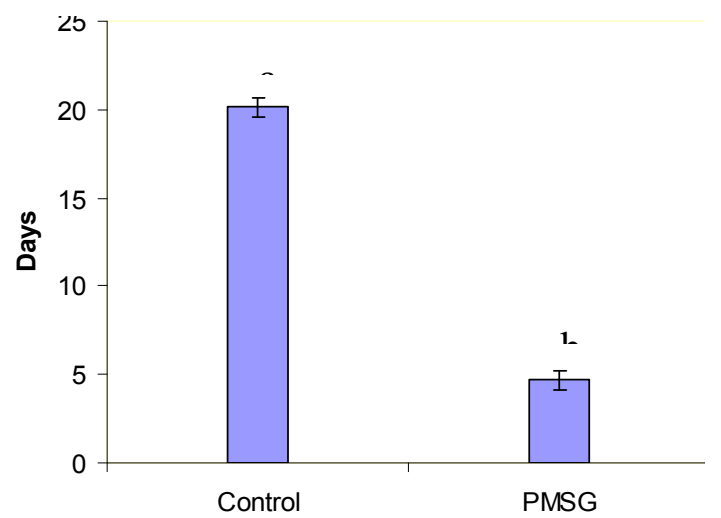

Fig. 1. Mean weaning to estrous interval in PMSG treated and Control groups (Superscripts $a$ and $b$ are significantly different $(P<0.05)$ between groups).

The mean litter size of the PMSG treated sows were $8.40 \pm 0.71$ piglets with a range of $3-15$ piglets and in control group it was $9.53 \pm 0.79$ with a range of 5-15 piglets. The mean litter size was not different between groups. The mean litter size of the Group 1 and Group 2 is shown on Table 2.

Table 2. The mean litter size of the PMSG treated and Control groups

\begin{tabular}{lll}
\hline Treatment group & $\begin{array}{l}\text { Mean litter size } \\
\text { (range) }\end{array}$ & $\begin{array}{l}\text { Gestation length } \\
\text { (days) }\end{array}$ \\
\hline $\begin{array}{l}\text { PMSG } \\
(\mathrm{n}=32)\end{array}$ & $\begin{array}{l}8.40 \pm 0.7 \\
(3-15)\end{array}$ & $113.14 \pm 0.4$ \\
$\begin{array}{l}\text { Control } \\
(\mathrm{n}=33)\end{array}$ & $\begin{array}{l}9.5 \pm 0 \\
(5-15)\end{array}$ & $113.9 \pm 0.6$ \\
\hline
\end{tabular}

Pregnancy rate in PMSG treated group (76.6\%) was significantly higher than that of the control group (39.39\%, Fig 2). 


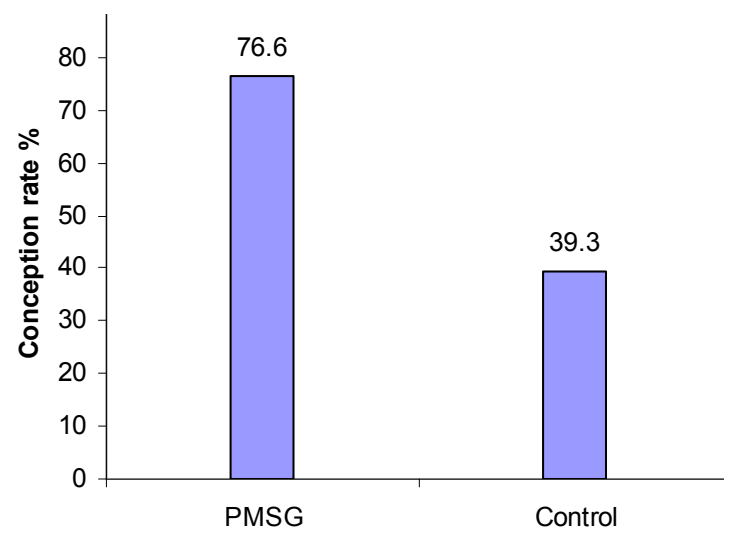

Fig. 2. Pregnancy rate in PMSG treated and control groups

Results were analyzed according to breeds of sows and shown in Table 3 . Within a group, mean weaning to estrous interval did not differ between different breeds of sows. However this parameter was significantly $(\mathrm{P}>0.05)$ different between groups. The highest pregnancy rate (PR) was recorded for Land Race breed in treatment group and PR in Large White and Durock breeds was $63 \%$ and $54 \%$, respectively (Table 3). PR of Landrace breed between groups were significantly different.

Table 3. Weaning to estrous interval, litter size and pregnancy rate of three breeds in PMSG treated group and control group.

\begin{tabular}{lllllcc}
\hline Breed & \multicolumn{2}{c}{ Wean to estrus Interval } & \multicolumn{2}{l}{ Litter size } & \multicolumn{2}{c}{ Pregnancy rate\% } \\
\cline { 2 - 7 } & PMSG & Control & PMSG & Control & PMSG & C \\
\cline { 2 - 7 } & & & & & & \\
Landrace & $5.2 \pm 1.1^{\mathrm{a}}$ & $19.9 \pm 2^{\mathrm{b}}$ & $9.7 \pm 1.1$ & $7.8 \pm 1.3$ & $79^{\mathrm{a}}$ & $40^{\mathrm{b}}$ \\
Large White & $4.2 \pm 0.4^{\mathrm{a}}$ & $21.4 \pm 1.1$ & $9.4 \pm 1.1$ & $9.6 \pm 2.0$ & 63 & 40 \\
Durock & $4.8 \pm 0.9^{\mathrm{a}}$ & $18 \pm 8.3^{\mathrm{b}}$ & $4.3 \pm 0.4^{\mathrm{a}}$ & $8.7 \pm 2.6^{\mathrm{b}}$ & 54 & 50 \\
\hline
\end{tabular}

Superscript $\mathrm{a}$ and $\mathrm{b}$ are in same row significantly differ $(\mathrm{P}<0.05)$ between groups

Litter size of Durock breed $(4.3 \pm 0.4)$ in PMSG treated group was small compared to Land Race $(9.7 \pm 1.1)$ and Large White breeds $(9.4 \pm 1.1)$. However this difference was not significantly different. Litter size in control group was not affected by the breed. However mean litter size of Durock breed was significantly different between groups (Table 4, Fig 3.) 


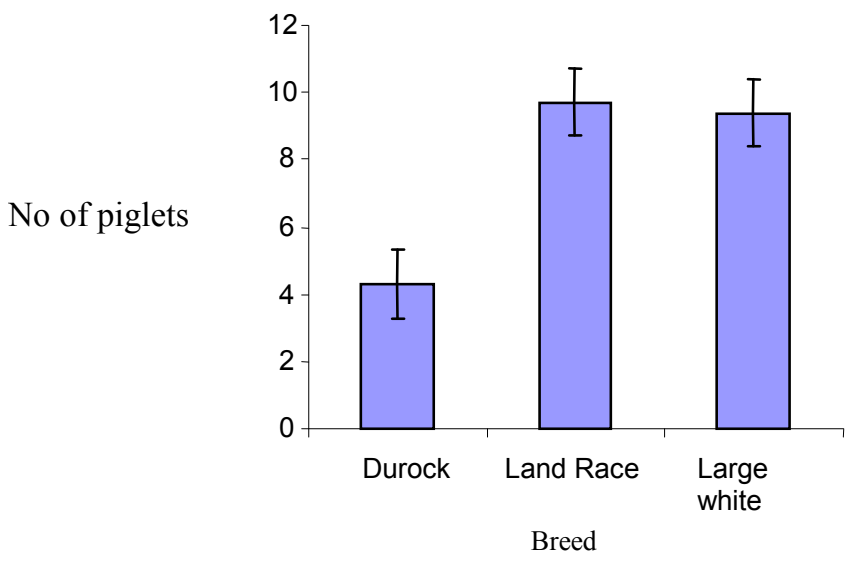

Fig. 3. Mean litter size at furrowing in PMSG treated three groups of sows

\section{DISCUSSION}

Weaning to estrus interval and litter size are two important fertility indices of pig farming. Reproductive efficiency in a sow is largely determined by these two parameters. Prolong post partum anoestrus in a sow could be due to several reasons; a) inhibition of hypothalamus - pituitary axis by lactational stimulus, b) failure to produce sufficient estrogen due to ovarian hypoplacia, c) cystic ovaries due to deficiencies in LH/FSH and d) failure to produce gonadotrophin hormone by anterior pituitary due to nutritional and vitamin deficiencies. Several studies carried out in the Europe have shown that lactational anoestrus may be due to inhibition of hypothalamus-pituitary gonadal axis by oxytocin rather than frailer to response to gonadotrophine (Crighton and Laming, 1969).

This study investigated the exogenous PMSG hormone administration at the time of weaning on few fertility parameters in sows under field conditions. Accordingly, the mean interval from weaning to estrus in the PMSG treated group (Group 1) was significantly lower $(\mathrm{P}<0.05)$ than that of the control group (Group 2) $(20.15 \pm 0.81$ days versus $4.7 \pm$ 0.51 days (Table 2, Fig 1). Similar results have been reported by Heitman et al. (1946) where PMSG was given 40 days after farrowing (Heitman and Cole 1956; Coles and Hughes 1946). This could be due to the direct activity of exogenous PMSG on the developing antral follicles and enhanced their development to preovulatory follicles or Graafian follicles showing estrus signs in sows. Our results clearly indicate that treatment with PMSG at the time of weaning has significantly $(\mathrm{P}<0.05)$ decreased the weaning to estrus interval in sows. It has also been shown that by giving combination of PMSG and hCG 2 days prior to weaning reduced weaning to estrous interval to $4.5 \pm 0.2$ (De Renis et al., 2003). It was also evident from this study that PMSG induced weaning to estrus interval was not affected by the breed of the sow. Therefore, the long post partum anoestrus (weaning to estrous interval) in sows kept under local conditions can be terminated if PMSG is administered at weaning. It seems that anoestrus sows have some follicular turn over at the ovary and insufficient ganadotrophine hormone production in the anterior pituitary has arrested the further 
follicular development causing ovulation. Nutritional deficiencies during lactation period causes negative energy balance in sow and this negative energy balance will cause changes in several growth factors such as insulin like growth factors (IGF). IGFs are known to play pivotal role in follicular selection and final oocyte maturation in many domestic animal species (Henry et al., 2001).

Poor nutrition therefore will lead to suboptimal ovarian function due to insufficient gonadotrophin and metabolic hormone secretion. This study has shown that most sows in the study responded to exogenous gonadotrophin (PMSG) suggesting that feeding during lactation is inadequate to resume cyclicity during postpartum. Therefore the improvement in feeding management during lactation and weaning period could result in reduce weaning to estrus interval in these sows. Ovulation rate and litter size decline after fourth litter(Hafez and Hafez, 2000).To minimize the effect of parity to the results all the sows were used in 13 parity.

Fertilization and conception rate to particular insemination primarily depends on timing of insemination and too early or delay insemination is the most common management problem for the lower conception rate in sows (Monik, 2006). Improper heat detection has been identified as the main reason for that. When insemination is carried out too late, eggs will degenerated at the time sperm reached to fertilization site and when early insemination is carried out sperms will lose their fertilizing ability at the time of ovulation.

Our results revealed that even though exogenous PMSG can significantly reduce interval from weaning to estrus it did not increase litter size or pregnancy rate. Breen et al. (2006) reported that treatment with exogenous PMSG does not affect litter size or pregnancy rate. Ovulation and fertilization may occur even in early postpartum period after treatment of PMSG/HCG but conception rate may low. Reduced fertility under these circumstances may be associated with unfavorable uterine environment and implantation failure (Hausteen et al., 1980). De Renis et al. (2003) have also shown that PMSG treatment did not have effect on conception rate or farrowing rate. In contrast, our results clearly indicate that pregnancy rate has significantly increase $(\mathrm{P}<0.05)$ in $\mathrm{PMSG}$ treated sows when compared to control group (76 \% versus 39.3\%, respectively; Table2, Fig 2). In this experiment sows were weaned eight weeks after farrowing. This has given enough time for uteri to be completely involuted and get rid of any uterine infections making the uterine environment more favorable for implantation. By this time sows have ample time to recover from the negative energy balance as well. Furthermore, injection of GnRH immediately after AI to PMSG treated sows might have also been contributed to higher conception rate. GnRH causes the preovulatory LH surge and ovulate more ova at correct time for fertilization. It should also mentioned here that heat detection in sows at field is rather poor and this will end up with too early or too late insemination causing lower conception rate and litter size. The results also revealed that there is no significant difference in litter size (survival rate) at day 30 between groups.

The mean weaning to estrus interval of PMSG treated group did not differ between breeds. When different breeds were considered, Durock breed in PMSG treated group had significantly small litter size compared to Land Race sows $(4.33 \pm 0.4$ and $9.78 \pm 1.10$, respectively). It was reported that breed or strain difference may exists on the occurrence of estrus during lactation (Burger 1952: Crighton, 1970; .Cole et al., 1972) and similarly response to PMSG might also be influenced by breed. However this has to be investigated further using large number of sows belong to different breeds. 
All AI in this experiment were done using semen from a one Largewhite boar. Therefore result of this study did not affect the boar.

\section{CONCLUSIONS}

This study showed that weaning to estrus interval in sows can be reduced when PMSG is injected immediately after weaning. Sows bred on PMSG induced heat and injected with GnRH following AI had significantly increase pregnancy rate only in Land Race and Large White breeds. However this was not associated with improvement in the litter size. Therefore, when sows are not returning to estrus following weaning, PMSG can be recommended to reduce the interval between weaning and estrus. Further this method can be used to synchronize estrus in wean sows. At present average litter size of AI sows in the range varies from 5 to 10 piglets. Proper heat detection and timing of AI is necessary to obtain good results from AI. Farmer training on heat detection will help in solving this problem to some extent. Double inseminations at 24 and 48 hours after standing heat also can be recommended to improve the conception and pregnancy rate in sow.

Weaning to estrus interval of PMSG treated sows was not affected according to the breed. However litter size of the PMSG treated Durock breed of sows had small litter size when compare to other breeds in same group or Durock breed in control group. Further studies are recommended to investigate effect of PMSG on litter size of Durock.

\section{REFERENCES}

Breen, S.M., Rodr Guez Zas, S.L. and Knox R.V (2006). Effect of PG 600 and adjusted mating times on reproductive performance in weaned sows. Theriogenology . PMED 16054308 .

Burger, J.F. (1952).sex physiology of pigs .Onderstepoort J..Vet Res.suppll.2:1

Cole, H.H. and Huges, E.H. (1946). Introduction of estrus in lactating sows with equine gonadotrophin J.Anim.Sci.5:25

Cole, D.J.A., Varley, M.A and Kay, R.M. (1972). Lactational anoestrus in the sow .Vet .Rec. 90:681

Crighton, D.B. (1970). Induction of pregnancy during lactation in the sow. J. Reprod. Fertil. 22:223.

Crighton, D.B and Lamming, G.E. (1969). The lactational anoestrus of the sow: the status of the anterior pituitary -ovarian system during lactation and after weaning. J. Endocrinal. 43:507

De Rensis, Benedetti, S., Siva, P. and Kirkwood. R.N. (2003). Fertility of sows following artificial insemination at gonadotrophin induced estrus coincident with weaning. Animal reproduction science, Apr 15;76 (3-4): 245-50 
Hafez, B. and Hafez, E.S.E. (2000). Folliculogenesis, Egg Maturation and Ovulation, Transport and Survival of Gametes in Text book on Reproduction in Farm Animals $7^{\text {th }}$ Edition (edsB.Hafez and E.S.E.Hafez). IVF Andrology International Kiawah Island, South Carolina, USA.

Kuo, D.L.L.H., Hodson and Hausler (1976) Induction of ovulation, artificial insemination and conception in lactating sow. Proc. Inter.pig vet.soc.d.23

Monika Ptaszynska. ( 2006). Compendium of Animal Reproduction (Ninth Edition). Intervet International

Smith D.M.(1961) The effect of daily separation of sows from their litters upon milk yield, creep intake and energic efficiency. Newzeland Agr.Res.4:232.

Zak, L., Foxcroft, G.R., Aheme, F.X. and Kirkwood, R.N. (2007).Reproduction in domestic Animals volume 43, issue 4, pages 445-450. 